\title{
Seismic Behavior of Offshore Wind Turbine with Gravity
}

\section{Foundation}

\author{
Hao Yu and Xiangwu Zeng \\ Department of Civil Engineering, Case Western Reserve University, Cleveland 44106, Ohio, USA
}

\begin{abstract}
The development of offshore wind energy becomes very fast in recent years due to its clean, safe, and high efficiency. However, the issue that quite a few offshore wind farms have been built in seismic active areas raises a great engineering challenge for the selection, design, and seismic evaluation of offshore wind turbine foundations. Earthquake is one of the most critical hazards for offshore wind turbines. The softening of soil due to pore water pressure buildup can sharply reduce the bearing capacity of the foundation, and consequently result in stability failure. The induced strong structural vibration has adverse impact on the normal operation of wind turbine as well as on the efficiency of power generation. In this study, a group of earthquake centrifuge tests was performed on a physical model of a wind turbine with gravity foundation. The seismic behavior of both the structure and the foundation soil was analyzed based on the recorded accelerations, pore water pressures, lateral displacements and settlements. The emphasis was on the interaction between foundation and soil. The results showed that gravity foundation can effectively resist the overturning moment induced by the superstructure. However, it was quite sensitive to the subsoil conditions. The large settlement and tilt in the offshore foundation might affect the performance of a wind turbine.
\end{abstract}

Key words: Offshore wind turbine, gravity foundation, seismic responses, centrifuge tests.

\section{Introduction}

For offshore wind farms located in seismic active regions, a great challenge has been the seismic analysis and design of the foundation for wind turbines. However, without any proven experience and failure cases, the studies on seismic resistance of offshore wind foundations are quite immature.

The gravity base is one of the most preferred foundations for offshore wind turbines as a result of its low installation cost. This type of foundation is widely used in shallow water with the depth of up to $20 \mathrm{~m}$, by directly sitting on the seabed or embedding some portion into the soil. The dimension of the reinforced concrete base typically ranges from $12 \mathrm{~m}$ to $18 \mathrm{~m}$ and the weight is up to thousands of tons [1]). Accordingly, the gravity foundation depends mainly on the massive self-weight to provide stability against the loads transferred either from the superstructure or

Corresponding author: Hao Yu, Ph.D., research field: geotechnical engineering. E-mail: hxy88@case.edu. from the surrounding soils and water.

The seismic analysis of gravity foundation for offshore wind turbines is particularly complicated due to the distinct structural features and harsh offshore environment. The stability of a foundation under earthquake loading is one of the most important issues. In particular, if the soil in the foundation is sand, the seismic-induced liquefaction might cause significant failures. Currently, the studies of wind turbine stability under earthquake conditions are based on the local building codes, i.e. Eurocode 8 [2], International Building Code [3], and American Society of Civil Engineers 7-05 [4]. However, these criteria cannot directly address the wind turbine problems because of the different structural properties. Quite a lot of model tests, both physically and numerically, were conducted on the similar structures under seismic loading (Yoshimi and Tokimatsu [5], Liu and Dobry [6], Bazeos et al. [7], and Chakrabortty et al. [8]). The results of those researches may help to understand the behavior of offshore foundations for wind turbines. 
The centrifuge test, as an accessible and economically viable modeling technique, has been widely used in the field of offshore engineering (Finn et al. [9], Madabhushi and Schofield [10], Martin [11]). In this study, a group of earthquake centrifuge tests was conducted on a wind turbine model with gravity foundation. The seismic behaviors of the model were measured in both dry and saturated condition in order to compare the seismic resistance of gravity foundation for onshore and offshore turbines. In addition, the soil behaviors in the free field and adjacent to the foundation were studied in the two different conditions.

\section{Test Program}

\subsection{Test Facilities and Soil Deposit}

The wind turbine model was tested on the geotechnical centrifuge at Case Western Reserve University. The centrifuge has a $1.37 \mathrm{~m}$ radius and 20 g-ton capacity. A hydraulic shaker designed by TEAM Corporation is mounted on the centrifuge platform. It can generate 1-D earthquake shaking during the flight. The details of the Case Western Reserve University centrifuge were reported by Figueroa et al. [12]. The container is a rigid rectangular box with internal dimensions of $53.3 \mathrm{~cm}$ (length) $\times 24.1 \mathrm{~cm}$ (width) $\times$ $17.7 \mathrm{~cm}$ (height).

The soil layer was constructed at $1 \mathrm{~g}$ ( $\mathrm{g}=$ acceleration of gravity) by using the well graded Toyoura sand with $D_{50}=0.17 \mathrm{~mm}$. The sand was uniformly poured from the height of $80 \mathrm{~cm}$ to keep the relative density at about $68 \%$. The thickness of soil deposit was $4.5 \mathrm{~m}$ (in prototype scale under $50 \mathrm{~g}$ ). In saturated tests, the soil was saturated by de-aired water under vacuum. The water table was maintained $1.5 \mathrm{~m}$ above the ground surface to simulate the offshore condition.

\subsection{Model Configuration and Test Procedures}

The model was prepared according to the structural features of offshore wind turbines in the real situation, which can be divided into three parts: tower head, wind tower, and foundation. As shown in Fig. 1, the tower head was simplified as a lumped mass, including the mass of the nacelle, generator, gearbox, etc. at the top of the tower rod with large slenderness ratio. Such tower-like structure was expected to induce strong vibration and large overturning moment during the earthquakes. The gravity foundation was modeled by using an aluminum block which is much heavier than the superstructure. The gravity base was embedded $1.5 \mathrm{~m}$ in the soil to prevent lateral sliding and the average contact pressure of the structure on the subsoil was about $70 \mathrm{kPa}$. The details of each part were described in Table 1. It should be pointed out that due to the size limitation of the centrifuge model, the prototype structure simulated by the tests was about one fourth of the size of a typical offshore wind turbine. However, the essential characteristics of such a structure were captured by the model and the results of the study can still provide insights about the seismic behavior.

The testing model was instrumented by ACC (accelerometers), PPT (pore pressure transducers), and LVDTs (Linear Variable Differential Transducers). The detail model profile as well as the instrument layout was depicted in Fig. 1. A 1-D synthetic earthquake (Fig. 2) was applied along the base when the model spun to a $50 \mathrm{~g}$ gravitational field. In the meantime, acceleration, pore pressure and displacement time histories were recorded by the installed sensors. The settlements of both the structure and the soil were measured by the corresponding LVDTs. Centrifuge scaling laws [13] were employed to evaluate the corresponding prototype behavior of the model.

Table 1 Wind turbine models in the centrifuge tests.

\begin{tabular}{lll}
\hline Component & Dimension $(\mathrm{m})$ & Weight $(\mathrm{t})$ \\
\hline Tower head & $1.75 \times 1.75 \times 1.25$ & 10.6 \\
Wind tower & $L=13 ; D=0.5$ & 6.25 \\
Gravity base & $3.75 \times 3.75 \times 2$ & 75.9 \\
\hline
\end{tabular}

In prototype units; $L=$ length; $D=$ diameter. 


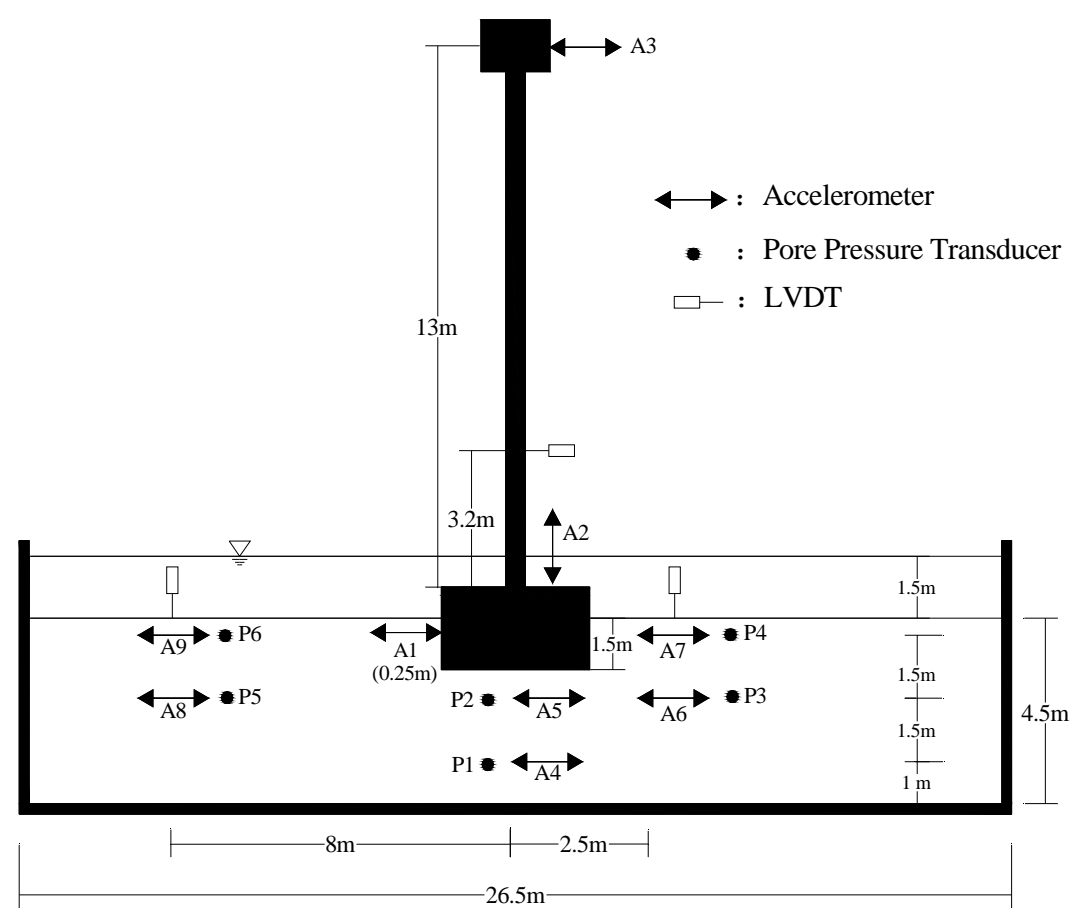

Fig. 1 Model configuration in the saturated tests (in prototype unit).

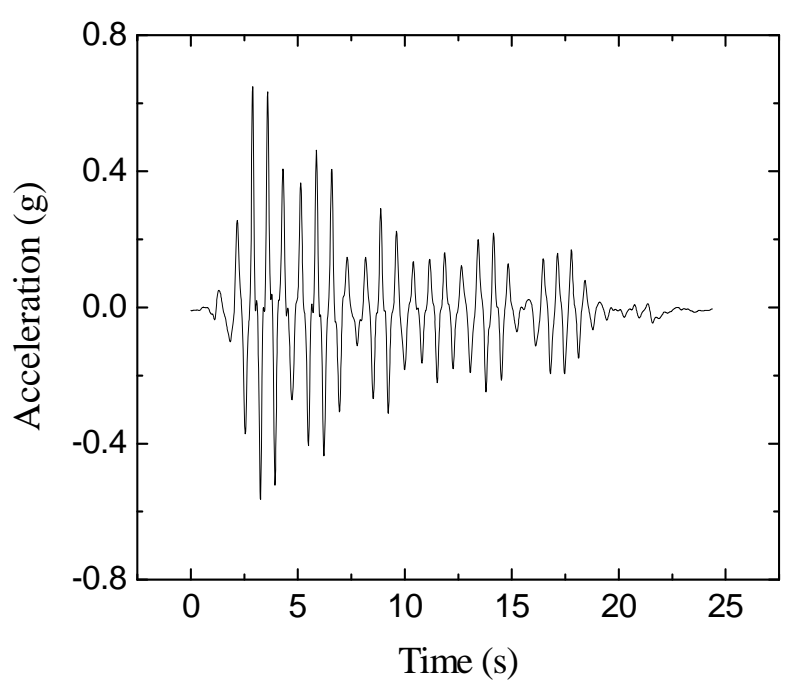

Fig. 2 Typical input acceleration.

\section{Test Results}

\subsection{Seismic Behavior of Model in the Dry Test}

The model test in dry condition was aiming to examine the behaviors of onshore wind turbine under earthquake loading. As shown in Fig. 1, the soil accelerations under seismic loading were measured in three different locations: underlying the structure (ACC4 \& 5); adjacent to the foundation (ACC6 \& 7); and in the free field (ACC8 \& 9) where the soil would not be affected by the structure or the boundary of container. In the dry tests, the recorded time histories of accelerations in the prescribed locations (Fig. 3) exhibited identical waveform and magnitude to the input motion as shown in Fig. 2. Therefore, the dense dry sand could be considered as an efficient media for seismic wave propagation.

A majority of earthquake energy imparted from the stiff soil to the embedded structure. Consequently, there was relatively strong response measured in the gravity base by ACC1 and in the tower head by ACC3 (Fig. 4a). ACC2 was installed vertically on the foundation but some distance away from the center (Fig. 1). Thus the recorded time histories by ACC2 could, to some extent, represent the rocking condition of the gravity foundation, which seemed negligible in the onshore condition. The lateral displacement of the turbine was illustrated in Fig. 5a. The residual displacement of the structure was quite small during the seismic loading. Even during the strong shaking period, the huge mass of gravity base foundation could provide enough stability to the superstructure 

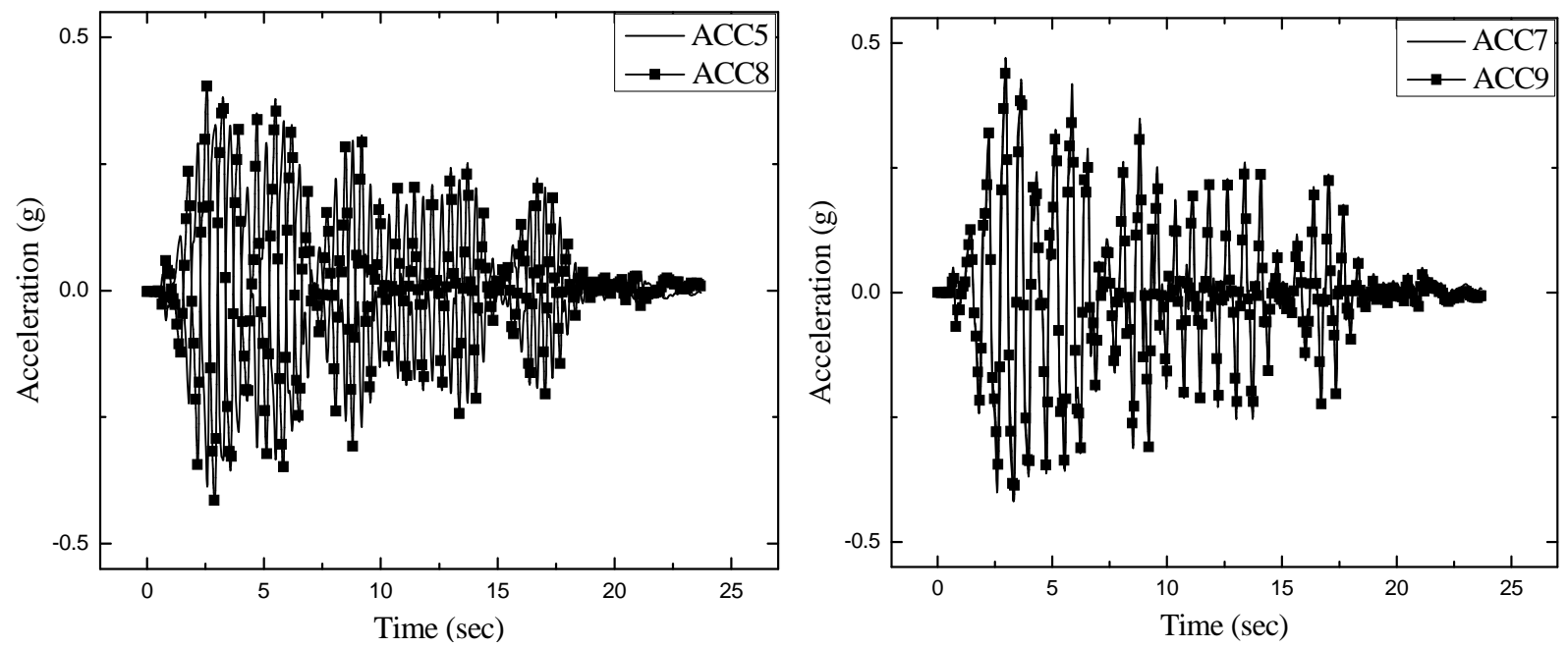

Fig. 3 Recorded time histories of accelerations in the dry soil.

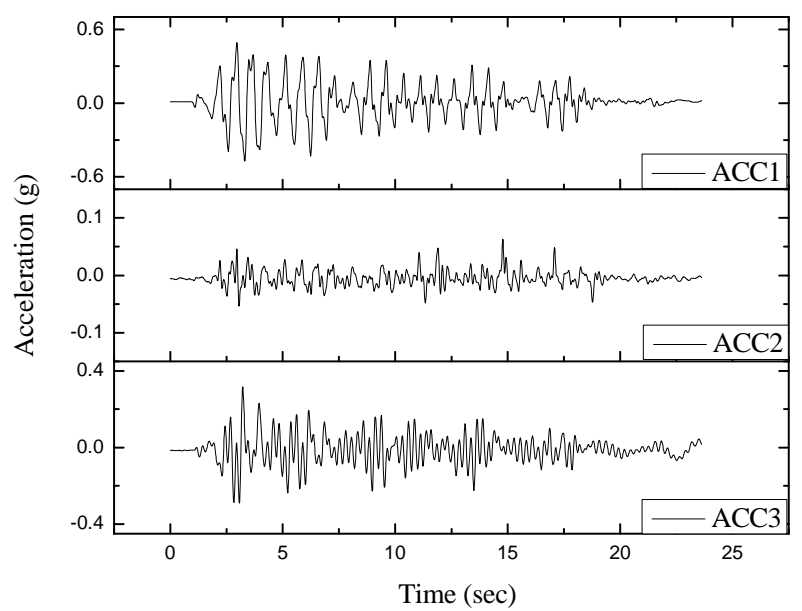

(a)



(b)

Fig. 4 Accelerations of gravity model in (a) dry test and (b) saturated test.

against the dynamic vibration.

Fig. 6 compared the recorded settlements of the wind turbine structure and the ground surface. It was found that the settlements in the dry condition were quite insignificant. The soil layer was compacted by only $6 \mathrm{~cm}$ after shaking. And the structure settled even less than the ground surface. However, there were many obvious oscillations in the time history curve, which might reveal the rocking of the foundation. In addition, little difference was observed between the settlements in the adjacent field and in the free field. Therefore, in the dry condition, the existence of structure might not influence the seismic behavior of adjacent soils.

\subsection{Seismic Behavior of Model in the Saturated Test}

The model test was performed in the saturated condition in order to simulate the offshore wind turbine under earthquakes. In this case, the soil showed quite different behaviors in the different locations due to the development of pore water pressure. The pore pressure transducers were installed in pair with the accelerometers at the corresponding locations (Fig. 1).

The existence of water has also largely changed the structural behavior during the earthquake. The extensively excess pore water pressure softened the soil layer and consequently increased the soil damping 


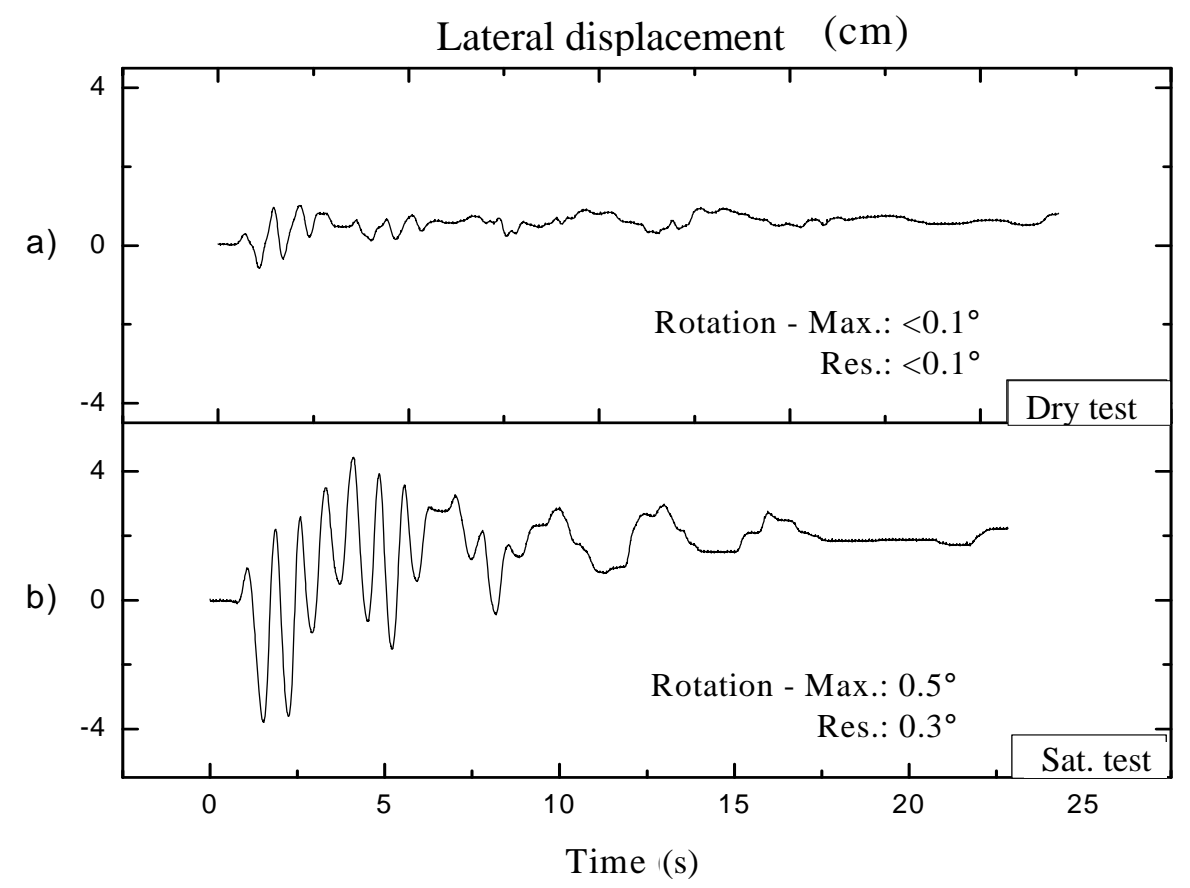

Fig. 5 Recorded time histories of superstructure lateral displacements in (a) dry test, (b) saturated test (Max. = maximum rotational angle; Res. = residual rotational angle).

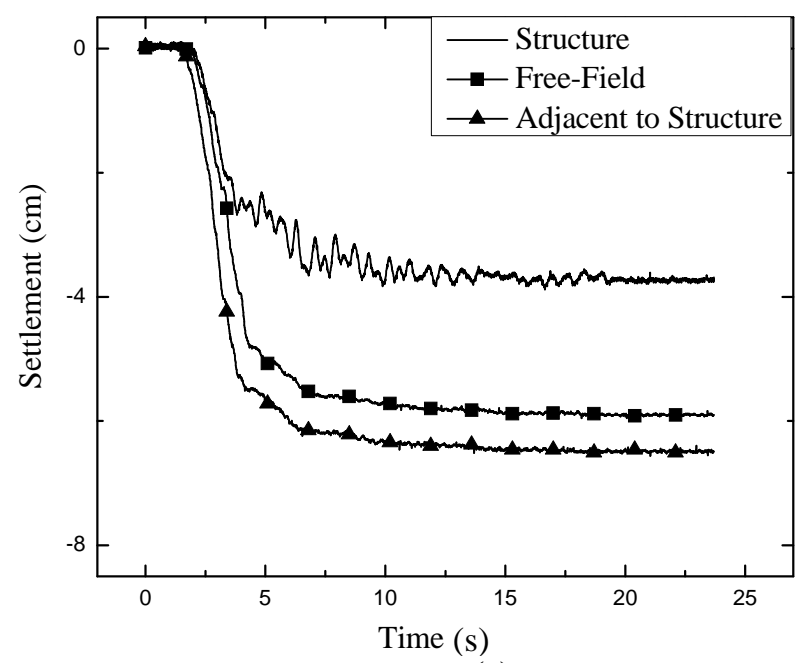

(a)

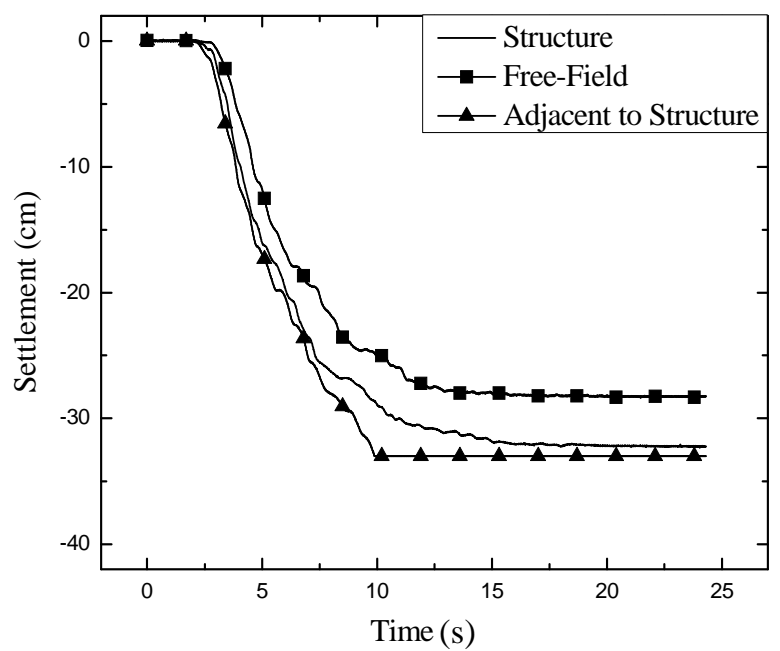

(b)

Fig. 6 Settlements of structure and ground surface in (a) dry test and (b) saturated test.

to the propagating earthquake energy. As seen in Fig. 4b, the recorded accelerations in the foundation (ACC1) and tower head (ACC3) were reduced compared with those in the dry condition. However, the rocking of gravity base (ACC2) was significantly amplified during the strong shaking. Accordingly, the vibration of superstructure was evidently increased. As shown in Fig. 5, the maximum lateral displacement during the shaking was about $4 \mathrm{~cm}$ in the saturated condition, which was much larger than that in the dry condition. However, the residual tilt was still within the acceptable level. The conclusion could thus be drawn that the gravity base foundation has a great resistance to the overturning moment during the seismic loading.

The settlements of structure and ground surface also exhibited huge difference in the saturated condition. As shown in Fig. 6b, the structure and ground sunk more than $25 \mathrm{~cm}$ which was much larger than those in 
the dry test. In particular, the structure settled a bit faster than the ground in the free field. It was observed that most part of the structural settlement occurred during the strong shaking (2-7 s) while the dissipation of pore water pressure after strong shaking contributed quite a small portion. In addition, the structural settlement surpassed the ground settlement in the free field, which might cause adverse impacts on the stability and normal operation of the wind turbine. Moreover, it was noticed that the settlements of soil in the adjacent field was larger than that in the free field, which might be affected by the interaction with the foundation.

According to Fig. 7a, the pore pressure ratios (ratio of increment of pore water pressure to the effective stress of soil) were compared in the depth $2 \mathrm{~m}$ under the ground surface. Clearly, the pore pressure ratio generated under the structure (PPT2) was much smaller than in the free field (PPT5). Correspondingly, the response measured by ACC5 under the structure (Fig. 8) did not change too much compared to that measured in the dry test. However, with the significant increase of pore water pressure in the free field, the soil was largely softened associated with the stiffness reduction in the soil near ACC8 (Fig. 8b) during the corresponding period 2-7 s. After that, pore water pressure began to dissipate and the soil

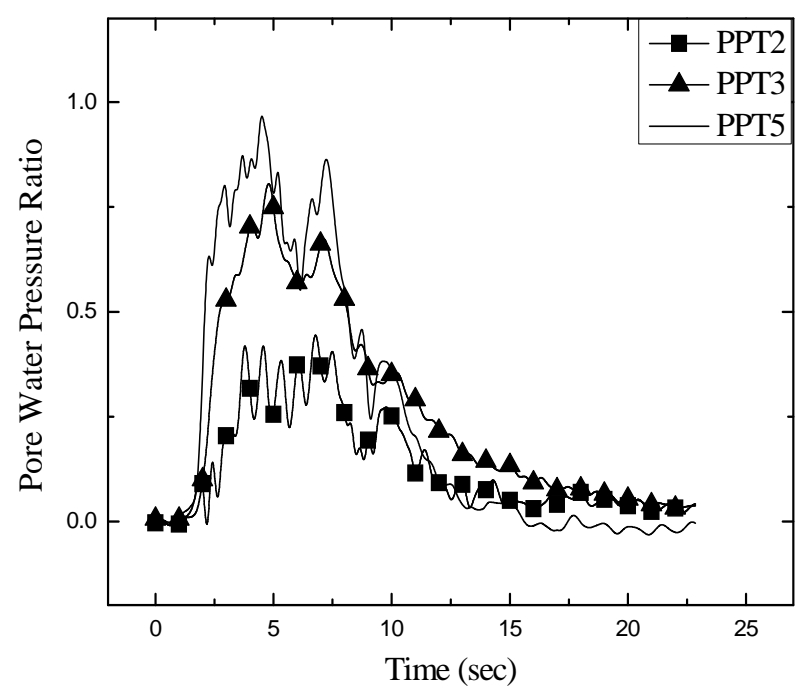

(a) gradually regained its stiffness.

In the top layer, the pore pressure ratio of soil in the free field reached to 1 at the 4th second (PPT6, Fig. 7b) when the soil was completely liquefied. The acceleration in ACC9 (Fig. 8c) was greatly attenuated and the liquefaction process lasted through the 12th second. The recorded pore pressure ratios in the soil adjacent to the foundation (PPT3 \& 4) were a bit smaller than those at the same depth in the free field (Fig. 7), which might be influenced by the confining pressure and the dynamic soil-structure interaction. Accordingly, the attenuations of soil responses in the adjacent field (ACC6 \& 7, Fig. 8), by contrast, seemed to be smaller during the strong shaking.

\section{Analysis of Testing Results}

The effectiveness of gravity foundation depends primarily on the soil condition, although it exhibited great seismic resistance to the overturning moment induced by the wind tower. In comparison of the onshore turbine and offshore turbine under the identical earthquake loading, it was found that the soil and structure exhibited quite different responses in these two conditions. The stiff dry soil could provide sufficient bearing to the wind turbine. In this condition, the structural settlement and tilt were minimized. However, the pronounced seismic response in the

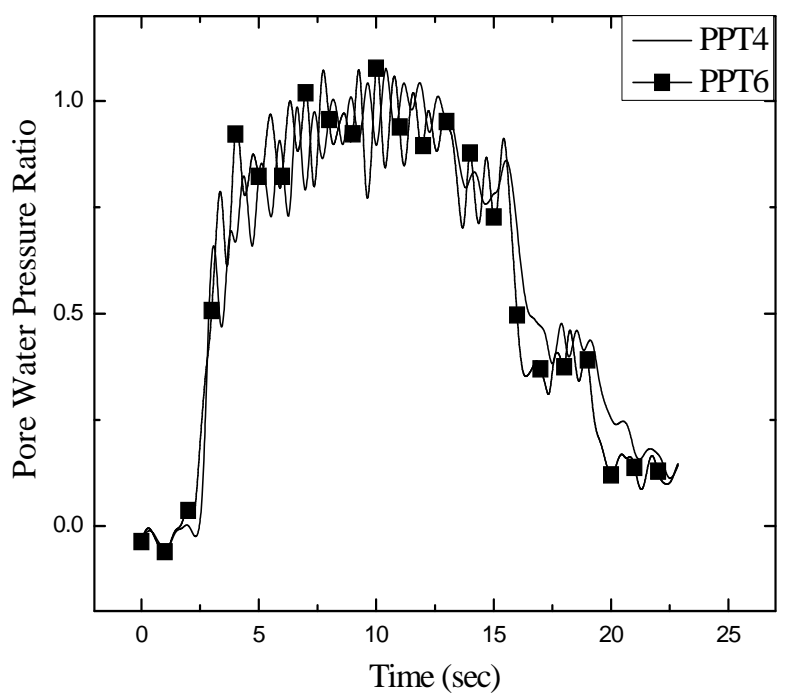

(b)

Fig. 7 Recorded time histories of pore pressure ratio in the saturated soil. 




(a)

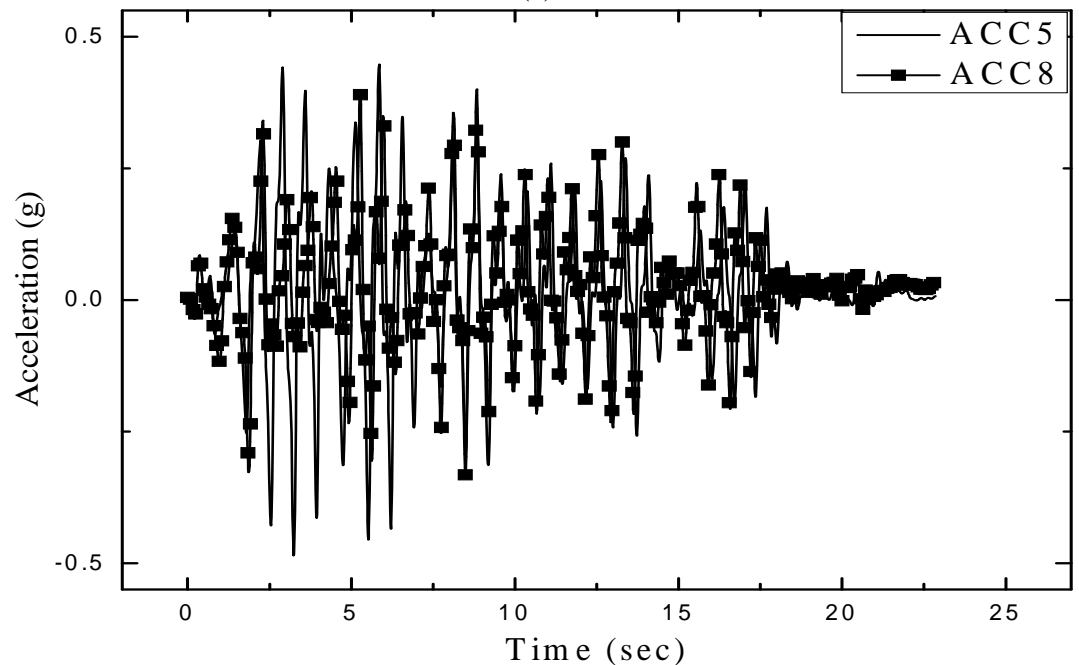

(b)

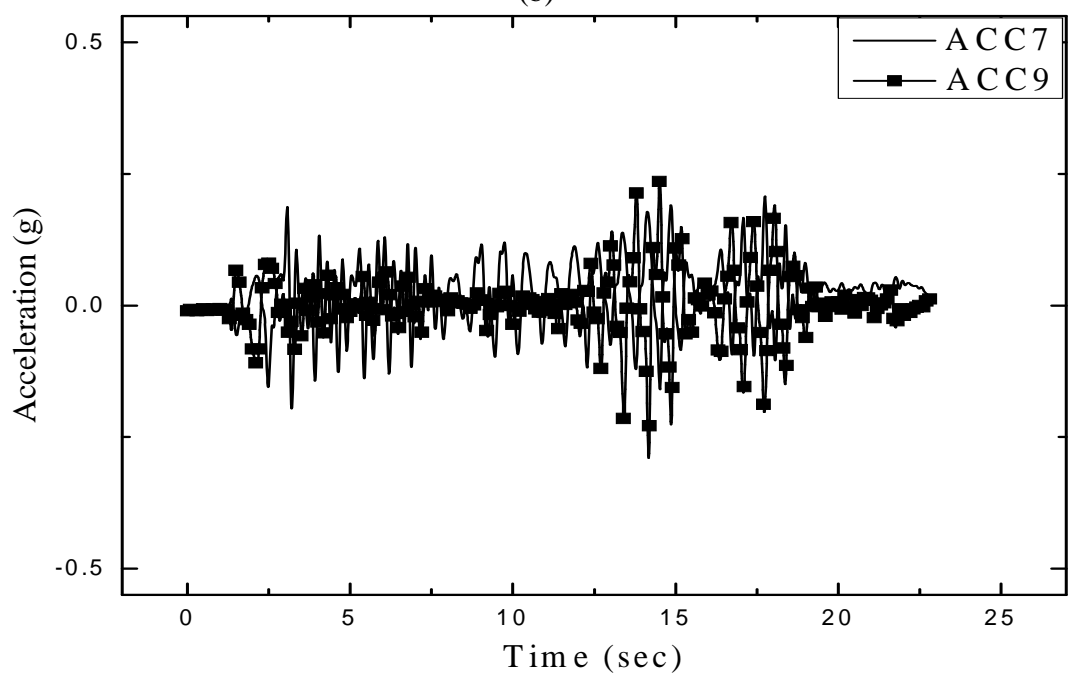

(c)

Fig. 8 Recorded time histories of accelerations in the saturated soil. 
foundation and superstructure would amplify the dynamic vibration imposed on the onshore wind turbine. On the other hand, the softened soil in the saturated condition could strongly attenuate the propagating seismic energy to the gravity base. But the excessive structural settlement was expected which may cause damage the offshore wind turbine [14].

In spite of the complexity and uncertainty, the SSI (soil-structure interaction) under earthquakes has been widely studied in recent decades, Stehmeyer, Bhattacharya and Adhikari [15-17]). The effect of SSI was expected to be more pronounced in the softer soil than in the stiff soil [18] (Rizos and Stehmeyer). By contrast, the frequency and response of structural motion in the saturated test decreased while the rocking of structure was amplified attributing to the buildup of pore water pressure under the structure. In addition, the soil around the foundation (PPT4) liquefied, at which time the lateral support of soil to the embedded portion of gravity base was totally lost. As seen in Fig. 5, the dynamic peak rotational angle increased from less than $0.1^{\circ}$ in the dry condition to $0.5^{\circ}$ in the saturated condition. It was also found in Fig. $7 \mathrm{a}$ that, due to the increased overburden pressure, the soil underlying the structure exhibited higher resistance to pore pressure generation. The excessive structural settlement was due not only to the compression of the soil layer, but also to the local subsidence induced by the amplified structural rocking. Similar researches have been conducted by Bartlett [19], Martin and Lam [20], Pecker and Pender [21], and Gajan et al. [14]. It was found that the amplified rotation periodically decreased the contact area of foundation base on each side. The yielding of soil underlying the base occurred, contributing to accumulated settlement of the structure by extruding the weakest soil away from underneath the structure [22]. In addition, the inertial force induced by superstructure vibration tended to amplify this mechanism. However, such deduction needs further validation by numerical analysis [23].
In the development of multi-megawatt offshore wind turbine, the gravity foundation with large mass and base area is needed to provide sufficient stability to the large-scale superstructure. However, the structural settlement and tilt are still the most challenging risks, which were found to be directly related to the contact pressure of the structure and its height/width ratio [24]. The mitigation schemes of shallow foundations under earthquakes have been widely researched. Most of efforts were spent on improving the structural design and employing alternative foundations (e.g., use pile foundations or new type gravity base foundation) [25]. However, the application of such schemes on offshore wind turbines needs to be validated in further studies.

\section{Summaries and Conclusions}

In this paper, a group of centrifuge model tests for seismic response of offshore wind turbine with gravity foundation have been performed in order to exam the structural stability. The model test in the dry condition simulated the condition of onshore wind turbine, which was also used to compare the seismic behavior with the offshore condition. Based on the measured responses in both soil and structure, the results can be concluded as:

(1) Gravity base foundation can provide sufficient stability in the onshore condition. However, the pronounced structural acceleration will amplify the dynamic vibration imposed on the onshore turbine.

(2) The offshore wind turbine with gravity base foundation exhibited great resistance to the overturning moment and toppling under earthquakes. However, the softened soil, due to the buildup of pore water pressure, tends to cause larger structural settlement and tilt in addition to the effect of soil-structure interaction.

(3) Without proven experience of offshore wind turbine under earthquake loadings, the analysis of structural behaviors and mitigation schemes for gravity foundation need to be further verified through 
physical modeling and numerical simulation.

\section{References}

[1] G. Gerdes, A. Tiedemann, S. Zeelenberg, Case Study: European Offshore Wind Farms-A Survey for the analysis of the experiences and lessons learnt by developers of offshore wind farms, Technical report for Pushing Offshore Wind Energy Regions, Deutsche Windguard Department, University of Groningen, 2006.

[2] Eurocode 8: Design provisions for earthquake resistance of structures, DD ENV 1998-1-1, BSI, 1996.

[3] International Building Code 2006, International Code Council, Country Club Hills, US, 2006.

[4] Minimum Design Loads for Buildings and Other Structures, ASCE 7-05, American Society of Civil Engineers, 2006.

[5] Y. Yoshimi, K. Tokimatsu, Settlement of building on saturated sand during earthquakes, Soil and Foundations 17 (1) (1977) 23-38.

[6] L. Liu, R. Dobry, Seismic response of shallow foundation on liquefiable sand, Journal of Geotechnical and Geoenvironmental Engineering 123 (6) (1997) 557-567.

[7] N. Bazeos, G.D. Hatzigeorgiou, I.D. Hondros, H. Karamaneas, D.L. Karabalis, D.E Beskos, Static, seismic and stability analyses of a prototype wind turbine steel tower, Engineering Structures 24 (2002) 1015-1025.

[8] P. Chakrabortty, R. Popescu, J.H. Prevost, Tower structures on liquefiable soil excited by random seismic input [CD-ROM], in: 9th ASCE Specialty Conference on Probabilistic Mechanics and Structural Reliability, ASCE, Albuquerque, NM, 2004.

[9] W.D.L. Finn, R.S. Steedman, M. Yogendrakumar, R.R. Ledbetter, Seismic response of gravity structures in a centrifuge, in: 17th Offshore Technology Conference, Houston, Texas, 1985.

[10] S.P.G. Madabhushi, A.N. Schofield, Centrifuge modeling of tower structure on saturated sands subjected to earthquake perturbations, Geotechnique 43 (4) (1993) 555-565.

[11] C.M. Martin, Impact of centrifuge modeling on offshore foundation design, in: Proceedings of International Symposium "Constitutive and Centrifuge Geotechnical Modelling: Two Extremes”, Ticino, Switzerland, 2002, pp. 135-153.

[12] J.L. Figueroa, A.S. Saada, H. Dief, Development of the geotechnical centrifuge at Case Western Reserve University, Centrifuge 98 (1) (1998) 3-8.

[13] A.N. Schofield, Cambridge geotechnical centrifuge operations, Geotechnique 30 (3) (1980) 227-268.
[14] S. Gajan, B. Kutter, J. Phalen, T. Hutchinson, G. Martin, Centrifuge modeling of load-deformation behavior of rocking shallow foundations, Soil Dynamic and Earthquake Engineering 25 (2005) 773-783.

[15] J. Stewart, R. Seed, G. Fenves, Empirical Evaluation of Inertial Soil-Structure Interaction Effects, Technical report for Pacific Earthquake Engineering Research Center, University of California, Berkeley, California, 1998.

[16] E.H. Stehmeyer, Computational simulations of linear soil-foundation-structure systems under dynamic and seismic loading, M.S. Thesis, Department of Civil Engineering, University of South Carolina, 2003.

[17] S. Bhattacharya, S. Adhikari, Experimental validation of soil-structure interaction of offshore wind turbines, Soil Dynamics and Earthquake Engineering 31 (2011) 805-816.

[18] D. Rizos, E. Stehmeyer, Simplified seismic analysis of soil-foundation-structure systems including soil-structure interaction effects, in: 13th World Conference on Earthquake Engineering, Vancouver, B.C., Canada, 2004.

[19] P.E. Bartlett, Foundation rocking on a clay soil, M.S. Thesis, University of Auckland, School of Engineering, New Zealand, 1976.

[20] G. Martin, I.P. Lam, Earthquake resistance design of foundation: Retrofit of existing foundations, in: Proceedings of GeoEngineering 2000 Conference, Melbourne, Australia, 2000, pp. 19-24.

[21] A. Pecker, M. Pender, Earthquake resistance design of foundation: New construction, in: Proceedings of GeoEngineering 2000 Conference, Melbourne, Australia, 2000, pp. 19-24.

[22] S. Dashti, J.D. Bray, J.M. Pestana, M.R. Riemer, D. Wilson, Mechanisms of seismically-induced settlement of buildings with shallow foundations on liquefiable soil, Journal of Geotechnical and Geoenvironmental Engineering 136 (1) (2010) 151-164.

[23] D. Pitilakis, M. Dietz, D.M. Wood, D. Clouteau, A. Modaressi, Numerical simulation of dynamic soil-structure interaction in shaking table testing, Soil Dynamics and Earthquake Engineering 28 (2008) 453-467.

[24] R. Sancio, J.D. Bray, T. Durgunoglu, A. Onalp, Performance of buildings over liquefiable ground in Adapazari, Turkey, in: Proceedings of 13th World Conference on Earthquake Engineering, 2004, pp. 935.

[25] U. Hartwig, T. Bierer, J. Sommer, Full-scale model tests on a gravity base foundation for offshore wind turbines, in: 21st International Offshore and Polar Engineering Conference, Maui, Hawaii, USA, 2011. 